\title{
Effect of Milrinone on Myocardial Mechanical Function and Cyclic AMP Content in the Fetal Rabbit
}

\author{
SHUN-ICHI OGAWA, TOSHIO NAKANISHI, KIYOMI KAMATA, AND ATSUYOSHI TAKAO \\ Pediatric Cardiology, Heart Institute of Japan, Tokyo Women's Medical College, Tokyo, Japan
}

\begin{abstract}
The effect of milrinone on mechanical function was studied in the isolated arterially perfused heart of the fetal (28th day of gestation) and newborn rabbits. The inotropic effect of milrinone in the fetus was significantly less than in the newborn. After milrinone infusion, myocardial cyclic AMP levels increased significantly in the two age groups and the fetal values before and after milrinone infusion were not significantly different from the newborn values. In our previous study the inotropic effects of dibutyryl cyclic AMP and high extracellular calcium in the fetus were significantly less than in the newborn. These data suggest that the diminished inotropic effect of milrinone in the fetus may be due, at least in part, to the decreased inotropism of cyclic AMP and calcium. (Pediatr Res 22: 282-285, 1987)
\end{abstract}

Abbreviations

IBMX, isobutylmethylxanthin

DT, developed tension

$\mathrm{RT}$, resting tension

$+\mathrm{dT} / \mathrm{dt}$ max, maximum rate of tension development

$1 / 2 \mathbf{R T}$, half-time to relaxation

Milrinone is a new analogue of amrinone and its inotropic effect has been evaluated mainly in the adult mammalian myocardium $(1,2)$. Although the precise mechanisms of the inotropic effect remain unclear, amrinone and milrinone may inhibit phosphodiesterase activity and increase myocardial cyclic AMP content (1-5). This may increase cytosolic calcium concentrations and cause a positive inotropic effect (2). Developmental changes in the effect of amrinone and milrinone have not been studied extensively. Binah et al. (6) showed that amrinone had a negative, rather than positive, inotropic effect in the newborn dog heart. Recently, a preliminary report of Binah et al. (7) showed that milrinone induced a minimal but significant positive inotropic effect in the newborn dog. The relationship between the inotropism of these drugs and cyclic AMP metabolism in the fetal and newborn myocardium remains unclear. Therefore, this study was designed to investigate the effect of milrinone on 1) mechanical function and 2) myocardial cyclic AMP content in the isolated fetal and newborn heart of the rabbit.

Received December 1, 1986; accepted April 3, 1987.

Correspondence Toshio Nakanishi, M.D., Pediatric Cardiology, Heart Institute of Japan, Tokyo Women's Medical College, 10 Kawadacho, Shinjuku, Tokyo, Japan.

Supported by Research Grants 61770706 and 61770711 from the Japanese Ministry of Education, Science, and Culture and a grant-in-aid from Japan Research Promotion Society for Cardiovascular Diseases.

\section{METHODS}

The experiments utilized the fetus at the 28th day of gestation (term 31 days) and 3- to 5-day-old newborn New Zealand White rabbits. After the doe was killed by a sharp blow to the head the fetuses were delivered by cesarian section and used within $1 \mathrm{~min}$ after delivery. The fetal and newborn rabbits were killed by a sharp blow to the head. The heart was then excised from the chest cavity and used for mechanical function study.

Perfusion solution. The control Krebs-Henseleit solution contained in mM: $\mathrm{NaCl}, 118 ; \mathrm{KCl}, 6 ; \mathrm{CaCl}_{2}, 1.5 ;$ glucose, $6 ; \mathrm{MgCl}_{2}$, 1; $\mathrm{NaHCO}_{3}, 24 ; \mathrm{NaH}_{2} \mathrm{PO}_{3}, 0.436 . \mathrm{KCl}$ concentration was relatively high because at $6 \mathrm{mM} \mathrm{KCl}$ arrhythmia was observed less frequently than at $4 \mathrm{mM}$. Changing $\mathrm{K}^{+}$concentrations from 4 to $6 \mathrm{mM}$ did not alter mechanical function. The control solution was equilibrated with $95 \% \mathrm{O}_{2}$ and $5 \% \mathrm{CO}_{2}$ yielding a final $\mathrm{pH}$ of 7.35-7.42. Milrinone (a gift from Sterling-Winthrop) was freshly prepared by dissolving the powder in $0.5 \mathrm{~N}$ lactic acid and an aliquot was added to the perfusate to achieve final concentrations of $10^{-5}$ to $510^{-4} \mathrm{M}$. An aliquot of $0.5 \mathrm{~N}$ lactic acid was also added to the control perfusate to achieve the same concentrations as the perfusate containing milrinone. IBMX (Nakarai) was suspended in the perfusate to achieve final concentrations of $10^{-5}$ to $10^{-4} \mathrm{M}$.

Experimental preparation. Experiments were performed in the isolated, arterially perfused ventricular preparation as described previously $(8-13)$. The aorta was canulated with PE-50 polyethylene canula and then perfused with oxygenated perfusate at a constant perfusion rate of $2.5 \mathrm{ml} / \mathrm{g}$ tissue per min using a Harvard pump. The base of the right and left ventricle was fixed between two Harmon forceps and the apex was attached to the Statham (UC 3) force transducer using a silk suture. The muscle was stimulated at $90 \mathrm{bpm}$, and its temperature was maintained at 37 $\pm 0.5^{\circ} \mathrm{C}$. In some experiments, the muscle was stimulated at 40 bpm and its temperature was maintained at $27^{\circ} \mathrm{C}$. The following parameters of mechanical function were monitored continuously: DT, RT, +dT/dt max, and $1 / 2 \mathrm{RT}$.

In the present study a whole heart was suspended at three points and DT represents one of three force vectors. Because the muscle preparation was not cylindrical, parameters of mechanical function were normalized for the wet weight rather than for the cross-sectional area. Although the papillary muscle preparation may be more desirable for a mechanical function study, the whole heart preparation was used in the present study to perform mechanical and biochemical studies in the same tissue. It must be noted, however, that although the heart weights changed with growth, the geometry of the preparation remained similar. It must be also mentioned that since the heart was perfused retrograde via the aorta, this preparation is different from the working heart model described by Neely et al. (20).

Experimental protocol. Initially the muscles were perfused with a control solution containing $1.5 \mathrm{mM}$ calcium for $60 \mathrm{~min}$ to 
allow for stabilization of the mechanical function. During the initial 40 min of each experiment. the length of the muscke preparation was adjusted so that the tension was equal to $90 \%$ of the maximal tension. After this initial period, both resting tension and the length-tension relationship remained unchanged under control conditions. The following studies were then performed.

Liffect of Milrinonce. After stabilization of mechanical function. the heart was perfused with solutions containing $1 \times 105.5 \times$ $10^{5}$, and $1 \times 10^{4}$ and $5 \times 10^{4} \mathrm{M}$ milrinone $(n=7 \mathrm{in}$ each age group). The duration of perfusion was $20 \mathrm{~min}$ at each milrinone concentration. Mechanical function reached a new steady state within 10 min after switching to a new milrinone concentration, and all measurements were made at 10 min.

In additional experiments, hearts were perfused with solutions containing lactic acid of the same concentrations as the perfusate containing milrinone. The duration of perfusion was similar to that described above.

In another series of experiments, the heart was initially perfused with a solution containing $5 \times 10^{4} \mathrm{M}$ milrinone for 10 min. After at new steady state was obtained. the heart was perfused with a solution containing both milrinone $\left(5 \times 10^{-4} \mathrm{M}\right)$ and 15 $\mathrm{mM}$ calcium for $10 \mathrm{~min}$ and whether in the heart perfused with solution containing milrinone contractile force can be increased further by an additional inotropic agent was studied.

Eiffer of IBMX. IBMX is a potent phosphodiesterase inhibitor $(2,3)$. The effect of IBMX was studied in a similar fashion described above $(n=6$ in each age group).

Parameters describing mechanical function were expressed as a percentage of control values and a $\mathrm{g} / \mathrm{g}$ tissuc wet weight

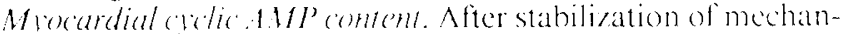
ical function, hearts were perfused with solutions containing $5 x$ $10^{4} \mathrm{M}$ milrinone or IBMX for 10 min and then frozen with metal clamps in licpuid nitrogen. (ontrol hearts were perfused with solutions which did not contain milrinone or $I B M X$ and frozen in liquid nitrogen. Muscles were then homogenized in ten volumes of $6 \%$ trichloroacetic acid using a ground-glass homogenizer and centrifuged at ()$^{\circ}($. The supernatant was neutalized by adding (aC ${ }^{\circ}()_{3}(14)$ and centrifuged again. ( yclic $\triangle M P$ concentration in the neutralized supernatant was measured by radioimmunoassay methods (15) using cAMP ['.5I] RIA Kit (Xew England Nuclear. Boston. MA).

Statistical analisis. Results were expressed as mean \pm SI: Statistical significance of the difference between group means was determined using the Student's / test (16). Percent changes were compared using nonparametric methods (Wilcoxon's rank sum test) (17). Statistical significance of response to milrinone and IBMX was analyzed using a paired $t$ test and repeated. measurements of analysis of variance. The probability was considered to be significant if the $p<0.05$.

\section{RISULTS}

Mechanical function data under control conditions in the fetus were not significantly different from those in the newborn (Table 1). Although I) I was slightly lower than the previous data (8). we thought that the present preparation was acceptable because myocardial high encrgy phosphate concentrations in muscies which showed mechanical function similar to the present data were not depressed (12). Furthermore, in a preliminary experi-

Table 1. Baseline data of incethanical function *

\begin{tabular}{|c|c|c|c|}
\hline$\wedge \mathrm{ge}$ & $\begin{array}{l}\mathrm{RI} \\
(\mathrm{g} / \mathrm{g} \\
\mathrm{t}\end{array}$ & $\begin{array}{c}\text { 1) } \mathrm{I} \\
\text { (g/g } \\
\text { tissue) }\end{array}$ & $\begin{array}{l}+\mathrm{d} \mathrm{J} / \mathrm{dt} \max \\
(\mathrm{g} / \mathrm{s} / \mathrm{g} \text { tissue })\end{array}$ \\
\hline
\end{tabular}

$\begin{array}{llllll}\text { Fetus (28 days) } & 11 & 3.5 \pm 0.2 & 6.6 \pm 0.4 & 31.8 \pm 1.5 & 1.36 \pm 0\end{array}$ $\begin{array}{llllll}\text { Newhorn } & 14 & 3.0 \pm 0.2 & 7.0 \pm(0.2 & 34.8 \pm 0.7 & 1.33 \pm 10\end{array}$

* Values are means \pm SL: The data were obtained at $37^{\circ} \mathrm{C}$. There was no significant difference between the 28 -day fetus and newborn. ment the inotropic effect of high [Ca], and isoproterenol using the present preparation were identical to the previously reported datal $(8,12,13)$.

liffect of milrinene. L actic acid used in the present study (10 (o) $5 \times 10^{\circ} \mathrm{M}$ ) had no significant effects on mechanical function. Typical data of the experiments using milrinone are shown in Figure 1. Milrinone infusion caused significant increases in D) in the newborn, but not in the fetus. Significant difference in D I between the newborn and fetus were observed at concentrations of $10^{-4} \mathrm{M}$ and $5 \times 10^{-4} \mathrm{M}$ (Fig. 2). After milrinone infusion $+\mathrm{dT} / \mathrm{dt}(\mathrm{max})$ increased significantly both in the newborn and fetus but the increase in the fetus was minimal (lig. 3). At $5 x$ 10 ${ }^{*} \mathrm{M}$ milrinone. $+\mathrm{d} \Gamma / \mathrm{dt}(\mathrm{max})$ increased to $191 \pm 10^{\circ}$, of the
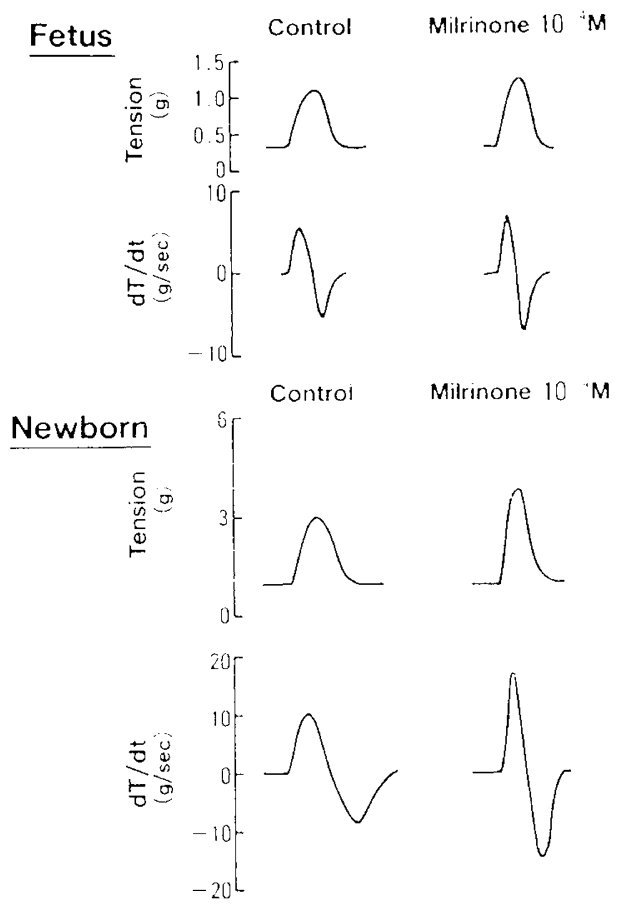

Fig. 1. Typical experiments that show the effect of milrinone on D) and $\mathrm{d} \%$ /dt. The experiments were performed at $37^{\circ}$ ( . The inotropic effect of milrinone in the fetus (28th day of gestation) was less than in the newborn.

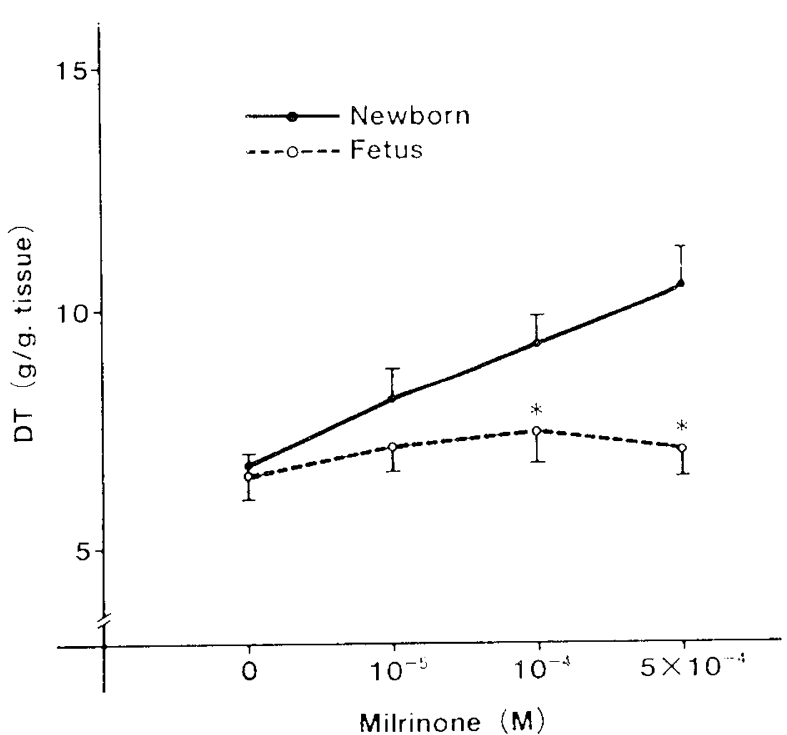

F.ig. 2. Effect of milrinone on I)T (temperature $37^{\circ}()^{\prime}$ * significantly $(p<0.05)$ different from the value in the newborn. 


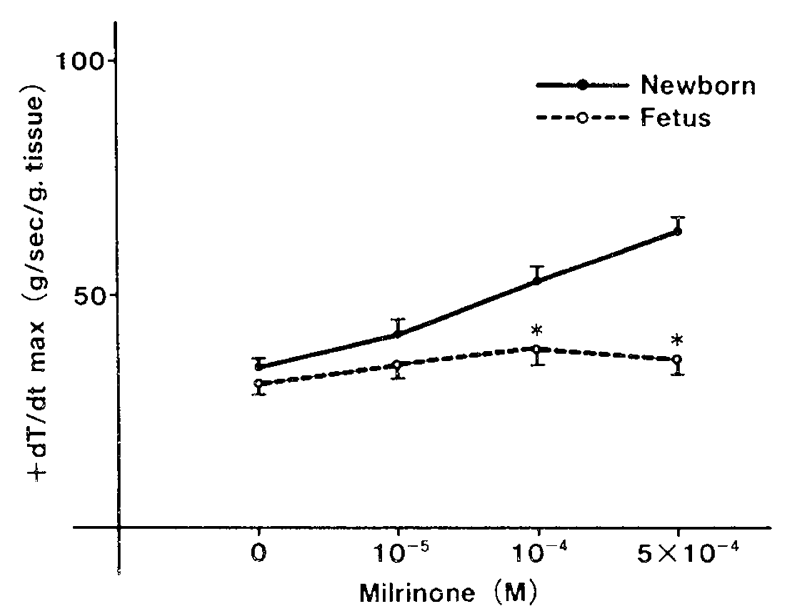

Fig. 3. Effect of milrinone on $+\mathrm{dT} / \mathrm{dt}(\max )$ (temperature $37^{\circ} \mathrm{C}$ ). * significantly different from the newborn value.

control in the newborn and only to $126 \pm 6 \%$ of the control in the fetus (significant difference between the newborn and fetus: $p<0.001)$. The inotropic effect of milrinone in the muscle maintained at $27^{\circ} \mathrm{C}$ was not significantly different from that at $37^{\circ} \mathrm{C}$ (Figs. 2 and 7 ). Milrinone $\left(10^{-5} \mathrm{M}\right)$ decreased $1 / 2 \mathrm{RT}$ similarly in the newborn and fetus (Fig. 4).

Since the inotropic effect of milrinone was minimal in the fetus, the inotropic effect of milrinone and high $[\mathrm{Ca}]_{\text {o }}$ was studied to examine whether other inotropic agent can increase $+\mathrm{dT}$ / $\mathrm{dt}(\max )$ further in the fetus. High $[\mathrm{Ca}]_{\mathrm{o}}(15 \mathrm{mM})$ caused additional inotropic effect in the heart perfused with milrinone in the fetus $(+\mathrm{dT} / \mathrm{dt} \max =185 \pm 37 \%$ of control, $n=4)$ and newborn $(265 \pm 25 \%, n=4)$.

Effect of IBMX. Whether the age-related difference in the inotropic effect of milrinone is observed in the other phosphodiesterase inhibitors was studied. After IBMX infusion, significant increases in DT and $+\mathrm{dT} / \mathrm{dt}(\max )$ were observed in the two age groups but the effect in the fetus was significantly less than in the newborn (Figs. 5 and 6 ).

Myocardial cyclic AMP content. The control value of myocardial cyclic AMP content was similar in the two age groups. Milrinone and IBMX infusion increased tissue cyclic AMP levels significantly, and the value after milrinone or IBMX infusion in the fetus was similar to the value in the newborn (Table 2).

\section{DISCUSSION}

This study demonstrated that in the isolated heart preparation the increase of DT and $+\mathrm{dT} / \mathrm{dt}(\max )$ during milrinone infusion in the fetus was less than in the newborn. This finding is in agreement with the data of Binah et al. (7) who showed that the inotropic effect of milrinone increased with age in the dog heart.

The present study also showed that the effect of milrinone on myocardial cyclic AMP levels was similar in the fetus and newborn. Therefore, it is unlikely that the decreased inotropic effect of milrinone in the fetus is explained by the response of myocardial cyclic AMP levels. Cyclic AMP, by activating protein kinase, enhances calcium release from the sarcoplasmic reticulum and causes an increase in intracellular calcium and a positive inotropic effect. Cyclic AMP also accelerates the relaxation process by stimulating calcium uptake by the sarcoplasmic reticulum. Different inotropic effects of milrinone in the newborn and fetus may be due to the age-related differences in 1) the process from cyclic AMP to sarcoplasmic reticulum and/or 2) the inotropic effect of calcium per se.

In the present study, enhancement of the relaxation process by milrinone, expressed as a shortening of $1 / 2 \mathrm{RT}$, was similar in the newborn and fetus. This suggests that the effect of milrinone on the sarcoplasmic reticulum is similar in the two age groups. One may argue that $1 / 2 \mathrm{RT}$ may not be related to the function of

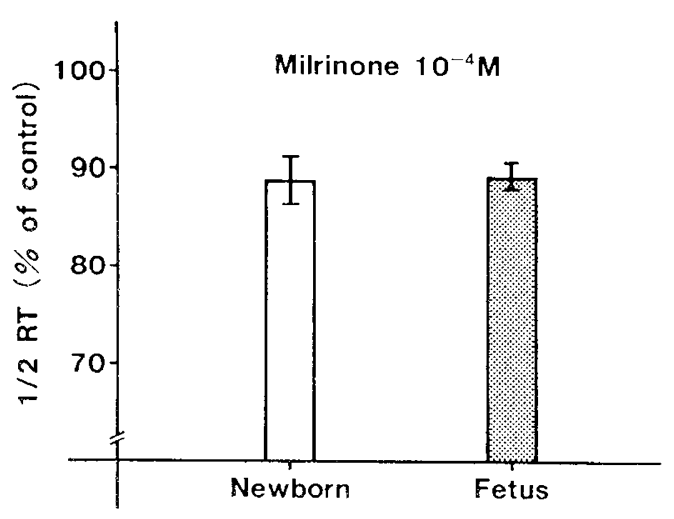

Fig. 4. Effect of milrinone on $1 / 2 \mathrm{RT}$ (temperature $37^{\circ} \mathrm{C}$ ). Shortening of $1 / 2 \mathrm{RT}$ in the fetus was not significantly different from the newborn value.

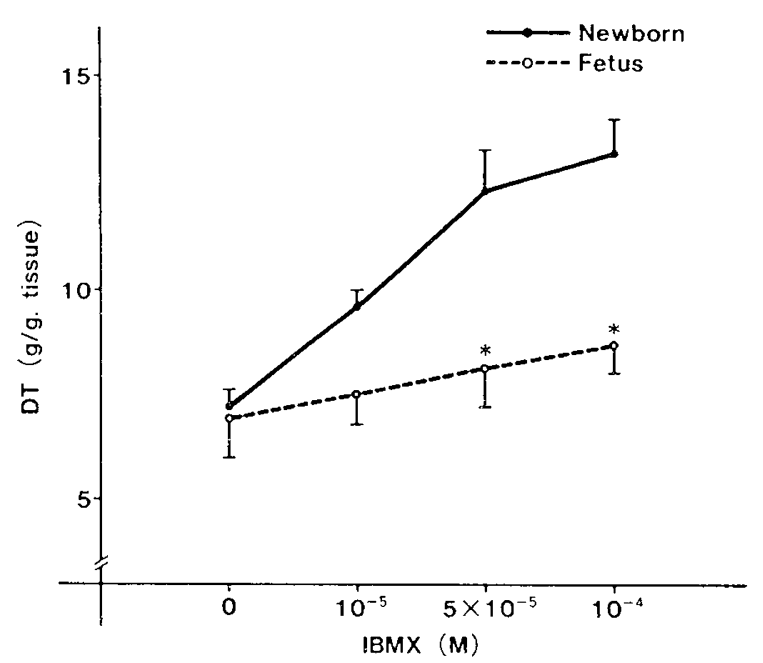

Fig. 5. Effect of IBMX on DT (temperature $37^{\circ} \mathrm{C}$ ). ${ }^{*}$ significantly different from the newborn value.

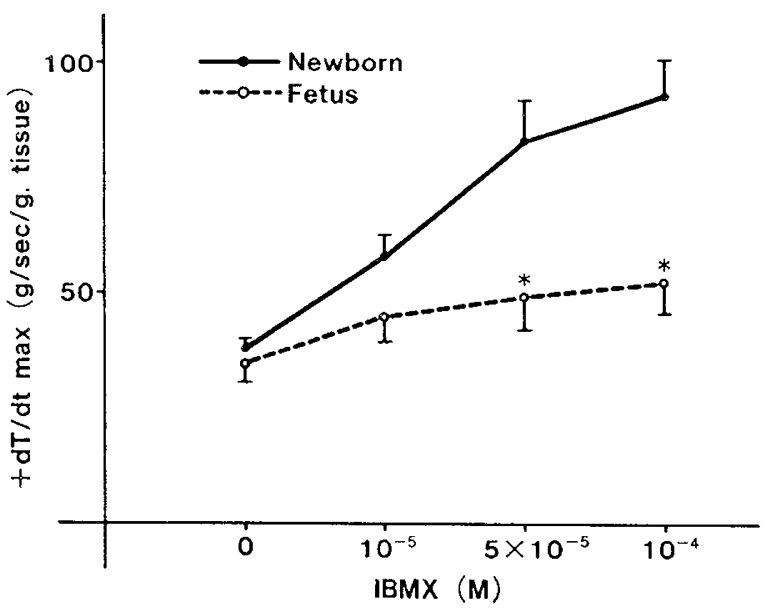

Fig. 6. Effect of IBMX on $+\mathrm{dT} / \mathrm{dt}(\max )\left(\right.$ temperature $\left.37^{\circ} \mathrm{C}\right){ }^{*}$ significantly different from the newborn value.

Ca sequestration by the sarcoplasmic reticulum but may be related to the function of the elastic elements of the preparation. However, when the heart was perfused with a solution containing ryanodine, an inhibitor of Ca uptake by the sarcoplasmic reticulum, $1 / 2 \mathrm{RT}$ prolonged significantly (data not shown). This suggests that $1 / 2 \mathrm{RT}$ is indeed related to the function of the sarcoplasmic reticulum. 
Table 2. Effect of milrinone and IBMX on tissue crelic AMP contents*

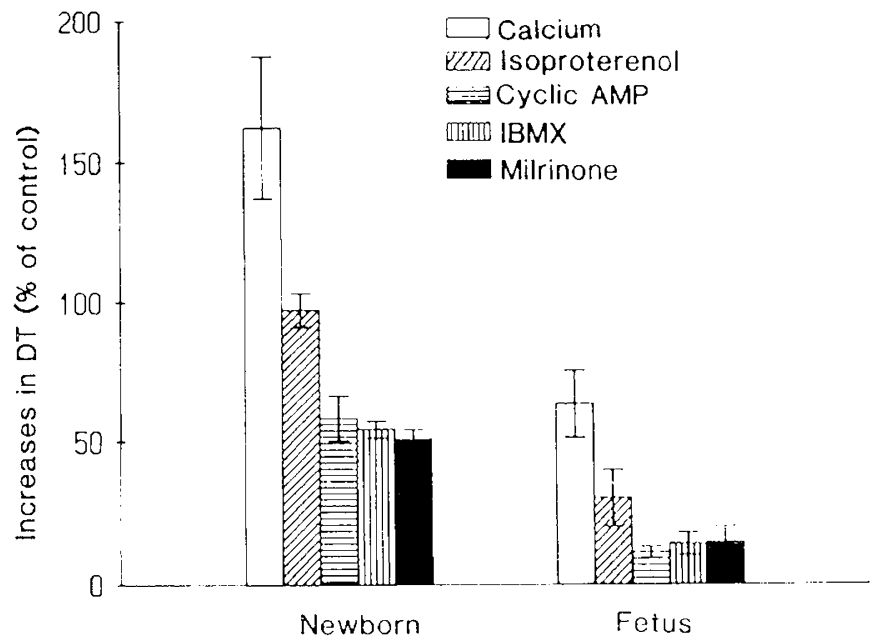

in present study, the maximal inotropic effect of both This suggests that the inotropic effect of phosphodiesterase inhibitors in general is diminished in the fetal myocardium. We have previously studied the inotropic effect of calcium $(15 \mathrm{mM})$. isoproterenol $\left(10^{5} \mathrm{M}\right)$, and dibutyryl cyclic $\wedge \mathrm{MP}\left(10^{4} \mathrm{M}\right)$ under the identical experimental conditions used in the present study $(8,13)$. The inotropic effect of dibutyryl cyclic $A M P$. which passes the cell membrane and activates protein kinase directly (17), was less in the fetal heart than in the newborn (Fig. 7). This supports the hypothesis that the diminished response to milrinone in the fetus resulted from the difference in the process after the cyclic $A M P$ increase.

Both milrinone and IBMX increase the amount of calcium reaching the myofilament and cause the inotropic effect. In our previous study, the inotropic effect of high [ $\mathrm{Ca}]_{\text {o }}$ in the fetus was diminished (Fig. 7). Therefore, it is likely that the decreased inotropic effect of milrinone in the fetus may be due, at least in part, to the age-related difference in the effect of calcium.

The precise mechanisms of the diminished inotropism of calcium in the fetus remained unclear but we postulated previously that premature development of the (a-sequestering ststem i.e. Sarcoplasmic reticulum (19), I tubular system. and mitochondria in the fetus resulted in the relatively high intracellular Ca concentration under control conditions (8). The higher c $y$ tosolic calcium in the fetus may enhance the contractility under control conditions but may prevent a further increase in contractile function at high $\left[(a]_{1}(8,18)\right.$.

One may argue that if milrinone enhance contractile force to the maximal level that the muscle can generate and if the amount of contractile protein in the fetus is less than in the newborn. the inotropic effect of milrinone might be diminished in the fetus. Indeed, Nakanishi and Jarmakani (8) showed that the amount of myofibrils in the fetus was less than in the newborn and this may explain the lower I) I (absolute value) in the fetus observed after administration of milrinone and other inotropic agents. In the present study, however, not only the absolute value of DI but also the relative change of I)T after administration of inotropic agents in the fetus was less than in the newborn. We have shown previously that the sensitivity of myofibrillar ATPase to calcium does not change with development. suggesting that [Ca $]_{1}$-tension relationship is similar in the newborn and fetus (18). Furthermore. in the heart perfused with milrinone. D) increased further after high calcium infusion. This suggests that milrinone infusion did not increase the contractile force to the maximal level that the muscle can generate. These data suggest that the diminished inotropic effect (relative change of D I') of milrinone and other inotropic agents in the fetus (Fig. 7) cannot be explained by the amount of contractile protein.

In conclusion, the present data indicate that in the isolated heart preparation the inotropic effect of milrinone in the fetus is less than that in the newborn. The diminished inotropic effect of milrinone in the fetus is not due to the decreased response of myocardial cyclic $A M P$ levels but may be due. at least in part. to the decreased inotropism of eyclic $\triangle M P$ and calcium.

Fig. 7. Comparison of milrinone with other inotropic agents. The data of ealcium, isoproterenol dibutvry evelic $A$ MP are from Reference 14. All experiments were performed at $27^{\circ} \mathrm{C}$ and the musele was stimulated at 40 $\mathrm{hpm}$. The effect of all inotropic agents studied in the fetus were approximately $30 \%$ of the newborn values.

\section{RHHRRONCH}

1. Alousi AA. Stankus (iP. Stuant JC. Malton 1.14 1983 (harackerization of the cardiotonic effects of milrinone a new and potent cardiac bipsidine on isolated tissues from sereral animal species. I (ardiowase pharmacol sis() 811

2. Scholz $1 \mathrm{f} 1984$ Inotropic drugs and their mechanisms of action. I Am coll (ardiol 4:389-39)

3 Fndoh $\mathrm{M}$ Yamashitas laira $\backslash 1982$ Positive inotropic eflect of amrinone in relation to cyelic nucleotide metabolism in the anine semricular musck I Pharmacol tixp ther $221: 775-783$

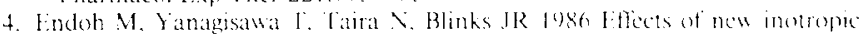
agents on creble nucleotide metabolism and calcum transients in anno entricular muscle. (irc $73($ suppl $[11): 117-1.33$

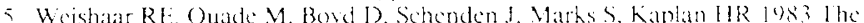
effect of sereral new and nowel cardiotenic agents on hey subcellular processes involved in the regulation of myocardial contractility. Drug 1) $3517-534$

6. Binah (). legato MJ. Danilo PJ. Rosen MR 198. Developmental (hanges in the cardias offects of amrinone in the dog (irc Res 57.747 .75 ?

7. Binaho (). Sodowick B. Vulliemo/ Y. Danilo P. Rosen M. 1986 The inotropic effects of amrinone and milrinone on neonatal and yeung canine cardia muscle. ("irculation 73 is suppl $[11): 40-50$

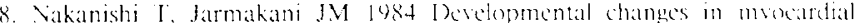
function and subcellular organclles im . Phosiol 246:11615.62:

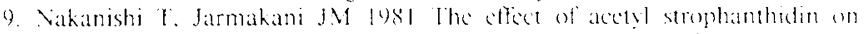
myocardiat function and potassium and calcium cxchange in the newhorn rabbit. Am J Physiol 241:116,37-6.45

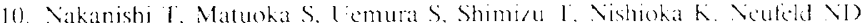

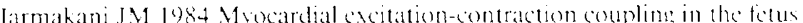
of the alloxan-diabetic rabbit. Pediatr Res $18: 1,344,1,34)$

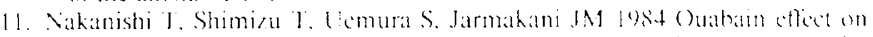
mocardial mechanical function and sodium pump in the fitus. A m l l'hysiol $246: 11213-11221$

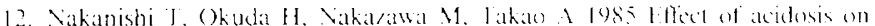
contractile function in the newborn rabbit heart. Pediatt Res 19:45? +15.

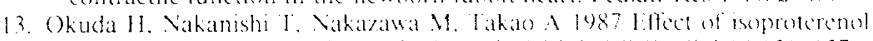
on mocardial function in the fetal rabhit. I Mol coll (ardiol 19:151 157

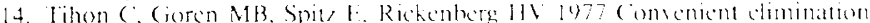

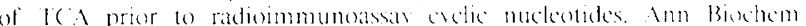
$80): 6,5360 ; 3$

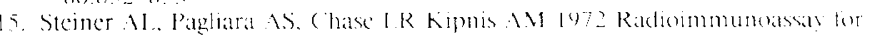
cretic nuckentides f Biol (hem 247:1114-1120

16. Snedecor (it) Cochran W(; 1970) Statistical Methexds. Iowa State l'niversits Press. Imes. In

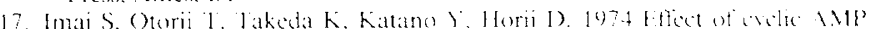
and dibutyry cectic AMP on the heart and coronar? circulation. lap I Pharmacol 20:-404)-. 510

18. Vakanishi T. Vagae .1. Takate \& 1986 Developmental changes in the contrate-

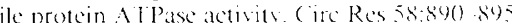

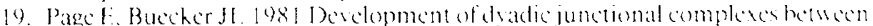
sarcoplasmic reticulum and plasmalemma in rabbit left wentricular myocardial cell. ( ire Res $48: 519-522$

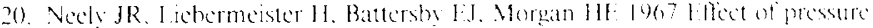

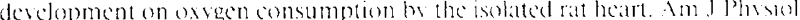
$212.804-814$ 